\title{
Ectinogonia buquetti Spinola (COLEOPTERA) VECTOR DE Ophiostoma stenoceras (Robak) Melin \& Nannf. EN BOSQUES DE Eucalyptus DE LA V REGION
}

\author{
(Ectinogonia buquetti Spinola (Coleóptera) vector of Ophiostoma \\ stenoceras (Robak)Melin \& Nannf. in Eucalyptus woods in the V Región) \\ *Eduardo Piontelli, **Ma.Antonieta Palma \& **Luis Torelli \\ *Universidad de Valparaíso, Escuela de Medicina, Cátedera de Micología \\ Casilla 92 V Valparaíso: e-mail ;<eduardo. piontelli@uv.cl> \\ **Laboratorio de Fitopatología SAG, Valparaíso
}

Palabras clave: Ectinogonia buquetti, Ophiostoma stenoceras, Eucalyptus

Key words: Ectinogonia buquetti, Ophiostoma stenoceras, Eucalyptus

\section{RESUMEN}

En un control fitosanitario efectuado en las provincias de San Antonio y Valparaíso, algunos árboles de plantaciones de Eucalyptus sp., presentaron un daño cortico vascular, síntomas de amarillez foliar y presencia de galerías subcorticales con compromiso medular, abundantes larvas de un coleóptero xilófago y presencia de micelio. Las muestras del tronco mantenidas en cámara de crianza por 45 días, permitieron la emergencia del estado adulto del insecto, determinándose como Ectinogonia buquetti Spinola (Coleoptera, Buprestidae). En los cultivos en cámara húmeda de la corteza afectada y del escarabajo en agar avena, se desarrolló además un hongo con abundantes peritecios negros de largos cuellos. Morfológicamente se clasificó como Ophiostoma stenoceras (Robak) Melin \& Nannf., con anamorfo en Sporothrix (Ascomycota, Ophiostomatales, Ophiostomataceae), determinación ratificada por M.J. Wingfield en Sud Africa. Su fase conidial es casi indistinguible del patógeno humano Sporothrix schenckii. Actualmente se considera como un saprófito o un fitopatógeno débil, sin registros aparentes en Chile.

Se aportan datos taxonómicos y filogenéticos actuales del complex $\boldsymbol{O}$. stenoceras, de sus integrantes en el suelo, madera de coníferas y su asociación a coleópteros vectores.

\section{INTRODUCCION}

Los hongos ophiostomatoides como Ceratocystis Ellis \& Halst. y Ophiostoma Syd.\& P. Syd. y sus anamorfos relacionados, se asocian aún para el micólogo a antiguas

\section{ABSTRACT}

During a phytosanitary control carried out in San Antonio and Valparaíso provinces, some trees belonging to Eucalyptus sp. plantations exhibited vascular cortical lesions, yellowish leaves signs and the existence of subcortical galleries involving some medular compromise together with a high number of xylophagous coleopteran larvae and presence of mycelia. Samples of the trunk which were kept in breeding chambers for 45 days allowed the emergence of the insect in its adult stage which was identified as Ectinogonia buquetti Spinola (Coleoptera, Buprestidae). In cultures of the affected bark kept in a humid chamber as well as the beetle put in oat agar, a fungus having abundant black long-necked perithecia was developed. It was morphologically classified as Ophiostoma stenoceras (Robak) Melin \& Nannf, with its anamorph in Sporothrix (Ascomycota, Ophiostomatales, Ophiostomatacea), a classification which was confirmed by M.J.Winfield in South Africa. Its conidial stage is almost undistinguished from the human pathogen Sporothrix schenckii. It is considered at present as a saprophyte or a weak phytopathogenous which lacks apparent records in Chile.Updated taxonomic and phylogenetic data of the O.stenoceras complex, about its components in the soil, conipherous wood as well as its association with coleopteran vector are supplied.

y confusas situaciones taxonómicas en la literatura, desde las primeras descripciones de sus integrantes hasta nuestros días (Hunt, 1956; Upadhyay, 1981; De Hoog \& Scheffer, 1984; Samuels 1993; Zhou et al., 2006; Zipfel et al., 2006). Estos 2 géneros cosmopolitas, forman complejas 
relaciones ecológicas y mutualísticas, no sólo con las plantas, sino con varios tipos de insectos vectores integrantes de los artrópodos (Coleoptera, Scolytinae), capaces de una dispersión activa de los numerosos propágulos (meio y mitosporas) viscosos de estos hongos, en especial los escarabajos de la corteza con Ophiostoma (Harrington, 2005). Estos insectos habitantes de la madera, capaces de formar túneles y galerías en diversos árboles forestales y ornamentales tales como: Pinus, Eucalyptus, Quercus, Populus, Malus, etc., permiten la dispersión fúngica por el xilema de la planta, interfiriendo en el flujo ascendente de agua en el árbol, que llevan a una decoloración y marchitamiento del follaje o causar otras importantes patologías especialmente en coníferas $(\boldsymbol{O}$. novo-ulmi y Ceratocystis fagacearum ) (Upadhyay, 1981; Kowalski \& Butin, 1989; Wingfield et al.,1993; Jacobs \& Wingfield, 2001).

Los objetivos de nuestro trabajo, consideraron: 1. Caracterizar e identificar el coleóptero presente. 2. Clasificar a nivel de especie el hongo asociado al insecto vector. 3.Aportar alcances taxonómicos y bibliográficos actuales relacionados con el espécimen aislado.

\section{MATERIALES Y METODOS}

Síntomas y obtención de los especímenes. Durante octubre del 2004, en plantaciones adultas de Eucalyptus sp. de 6 a 10 años, ubicados en las provincias de San Antonio y Valparaíso (V Región), se observaron: síntomas de amarillez severa en el ápice, un avance cortico vascular de color ambar a grisáceo,en la parte basal y cuello de los árboles, a veces con compromiso medular, galerías con larvas de un insecto xilófago junto a micelio fúngico y azulado de la madera (Figuras A y B).

Identificación del Coleóptero. Los trozos de corteza de Eucaliptus obtenidos con las larvas del coleóptero, se llevaron a cámara de crianza mantenidas a temperatura $\left(17-19^{\circ} \mathrm{C}\right)$ y humedad relativa ambiente $(70-80 \%)$ en el Laboratorio de Fitopatología Regional del SAG, Valparaíso. Se observó la emergencia de adultos en el transcurso de 45 días y para la identificación del insecto se empleó la monografía de Cobos, 1953.

Identificación del hongo. En los aislamientos obtenidos directamente de los trozos de corteza de Eucalyptus mantenidos en cámara húmeda a temperatura ambiente y durante 10-15 días. Las masas de esporas observadas fueron transferidas para su purificación a tubos de agua peptonada para su dilución seriada y luego sembradas en placas de agar malta durante 3 días a $20^{\circ} \mathrm{C}$ para la obtención de colonias puras. Las colonias puntiformes desarrolladas se transfirieron bajo la lupa a nuevos cultivos en agar avena y agar malta, incubándose en triplicado a 4 temperaturas: $25^{\circ} \mathrm{C}, 30^{\circ} \mathrm{C}, 32^{\circ} \mathrm{C}$ y $36^{\circ} \mathrm{C}$
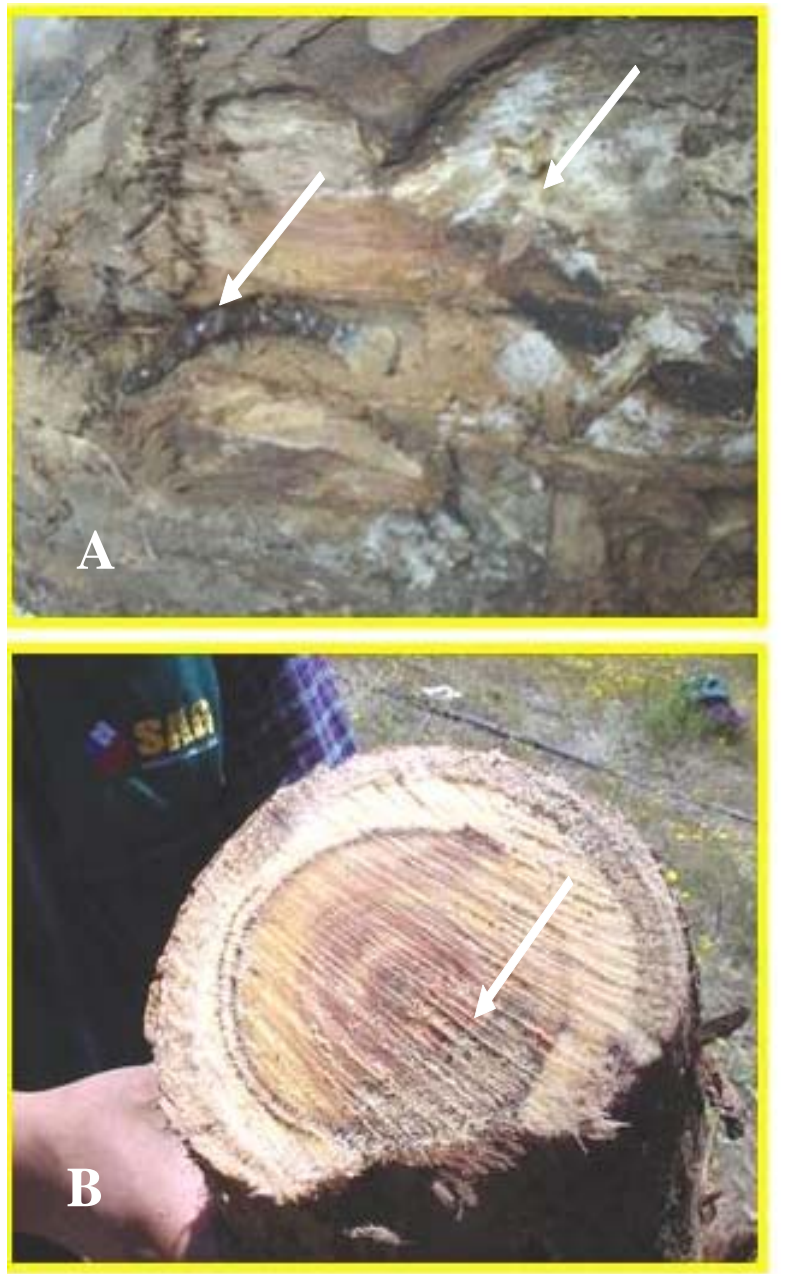

Figura A, B.- A. Trozo de corteza mostrando (flechas) las galerías formadas por las larvas del coleóptero y la presencia de micelio blanco. B. Vista del daño cortical lateral en el tronco y azulado de la madera (flecha).

$\left( \pm 1^{\circ} \mathrm{C}\right)$ durante 8 días. Además se efectuaron siembras en agar agua con trozos de madera de pino esterilizada como otro substrato natural durante $10-15$ días a temperatura ambiente $\left(18-20^{\circ} \mathrm{C}\right)$.

Para su determinación se emplearon las claves morfológicas de Upadhyay (1981) y las sinópticas de Grylls \& Seifert (1993).

\section{RESULTADOS}

\section{1. -Descripción del coleóptero. Ectinogonia} buquetti Spinola (Coleoptera, Buprestidae). Adultos de tamaño variable, fluctuando ente 18 a $26 \mathrm{~mm}$ de largo (Fig.1,2). Poseen una coloración cobriza a bronceada oscura, algo brillante en su parte inferior, encontrándose recubierta en vida por una exudación pulverulenta blanquecina. 

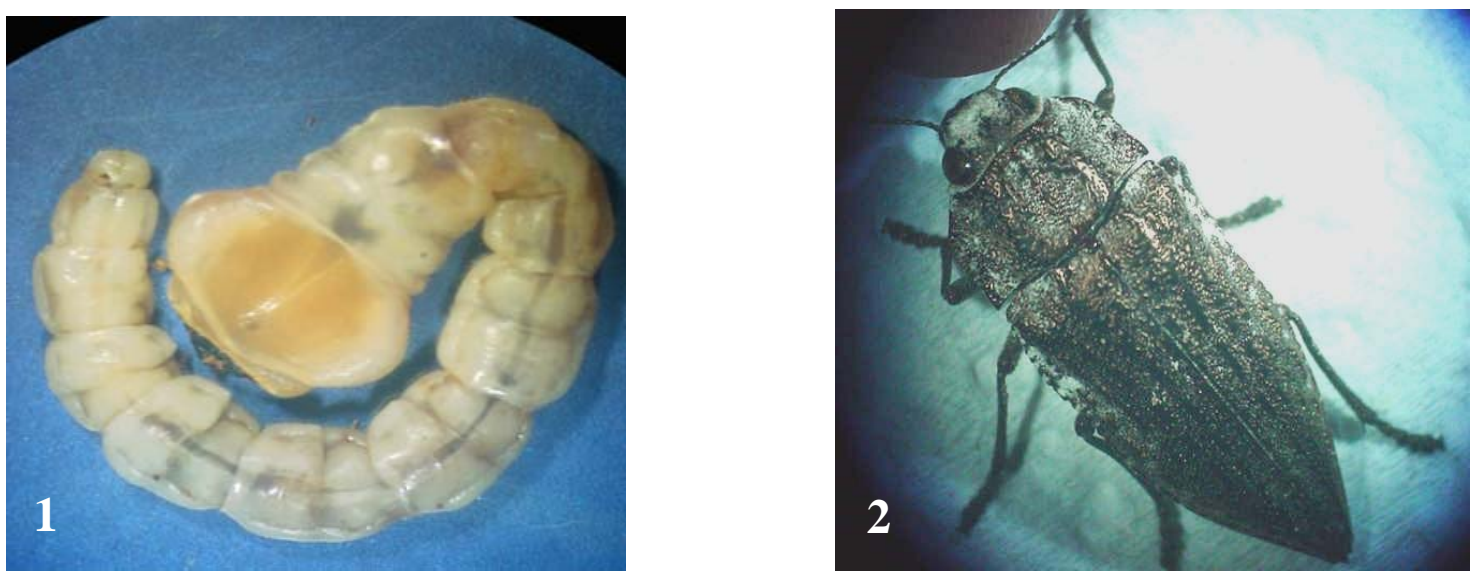

Figura 1.- Ectinogonia buquetti. 1,1. Estado larval del coleóptero; 1,2. Estado adulto

Escultura elitral bastante fina, a veces casi borrada, con la parte superior del cuerpo glabra (pronoto y élitros). Crenulación sub humeral en general muy fuerte, así como en los costados del pronoto, siendo los ángulos posteriores de estos subrectos. Cuerpo ancho, sub paralelo y muy acuminado hacia el ápice elitral.

Estado larval, de tamaño aproximado de $6 \mathrm{~cm}$, de color blanco cremoso (Fig. 1,1), con el primer segmento toráxico de mayor tamaño que los posteriores. Cabeza de color castaño oscuro. En el primer segmento toráxico se encuentra un espiráculo característico de la familia Buprestidae, de forma arriñonada o falcada.

\section{2.- Aspectos morfológicos de Ophistoma stenoceras (Robak) Melin \& Nannf.}

Sus características principales fueron: presencia abundante de ascomata superficiales negros, ya sea sobre trozos estériles de pino en agar agua, en agar avena y agar malta entre 7-10 días. La morfología más clásica se presentó en agar avena como en los trozos de pino. En agar avena: colonias inicialmente blancas, que se tornan grises a negruzcas al pasar los días debido al inicio de los ascomatas, $14-16 \mathrm{~mm}$ diam. en 8 días a $25^{\circ} \mathrm{C}$. Reverso crema a café oscuro. Micelio aéreo abundante, superficial, laxo a fasciculado, hialino, septado. Conidióforos abundantes, integrados, poco diferenciados o de diferentes dimensiones, a veces ramificados (15-38 $\mu \mathrm{m})$, células conidiógenas apicales laterales o integradas a las hifas. Cuando se presentan apicalmente sobre un corto conidióforo son variables en tamaño y de formas dilatadas, originando conidios simpodiales sobre cortos dentículos dispuestos en forma más o menos circular. Conidios holobláticos, hialinos, unicelulares, lisos, de paredes delgadas, clavados a elipsoidales, raramente subglobosos, dispuestos a menudo a semejanza de los pétalos de una flor (Fig.2, 6), agregados en el tiempo en masa mucoides (Fig. 2,5).

En una sola preparación teñida con lactofenol y azul de algodón de un aislado sobre madera, se observaron conidios secundarios, dispuestos lateralmente sobre las hifas, escasos, redondos a sub globosos de paredes gruesas, adquiriendo tonalidades café en el tiempo, de 3$4 \mu \mathrm{m}$ diámetro (Fig. 2,7).

Ascomata de bases globosas, 140 - $200 \mu \mathrm{m}$ de diámetro, superficiales o parcialmente inmmersos (Fig.2,1), ornamentados con hifas de difentes largos (50-160 $\mu \mathrm{m})$ café grisáceas; cuellos periteciales largos negruzcos, lisos, 310-1100 $\mu \mathrm{m}$, más anchos en la base $(22-40 \mu \mathrm{m})$ y adelgazándose en el ápice (11-15 $\mu \mathrm{m})$, con hifas ostiolares divergentes, simples o ramificadas, septadas $(25-40 \mu \mathrm{m})$ de color café claro en la base, hialinas hacia el ápice (Fig. 2,2-2,3). Ascos no observados, ascosporas hialinas alantoides, en forma de gajos de naranja, unicelulares, 2,5$4 \times 1,5-2 \mu \mathrm{m}$, sin vaina mucilaginosa (Fig. 2,4).

\section{DISCUSION}

Las larvas de este coleóptero son esencialmente rizófagas - endófitas y aunque afectan varias familias de angiospermas, no se habían observado hasta la presente nota en la familia Mirtaceae (Eucalyptus spp.). Según el entomólogo nacional Tomás Moore (comunicación personal), este evento constituye la primera detección del insecto sobre Eucalyptus sp. en el país. Para Cobos (1953), corresponde a una especie nativa de Chile y posee una gran plasticidad etológica y capacidad adaptativa que la señalan como una potencial plaga de importancia fitopatológica por los daños que ocasiona a las raíces de sus hospedadores. Casos similares de adaptación de insectos endémicos a las plantas cultivadas de origen exótico se comprueban día a día con resultados nefastos para los cultivos.

El patrón de comportamiento del Coleóptero debido a la modificación de los factores ecológicos ambientales, pudo ser la causa del cambio de hospedador 

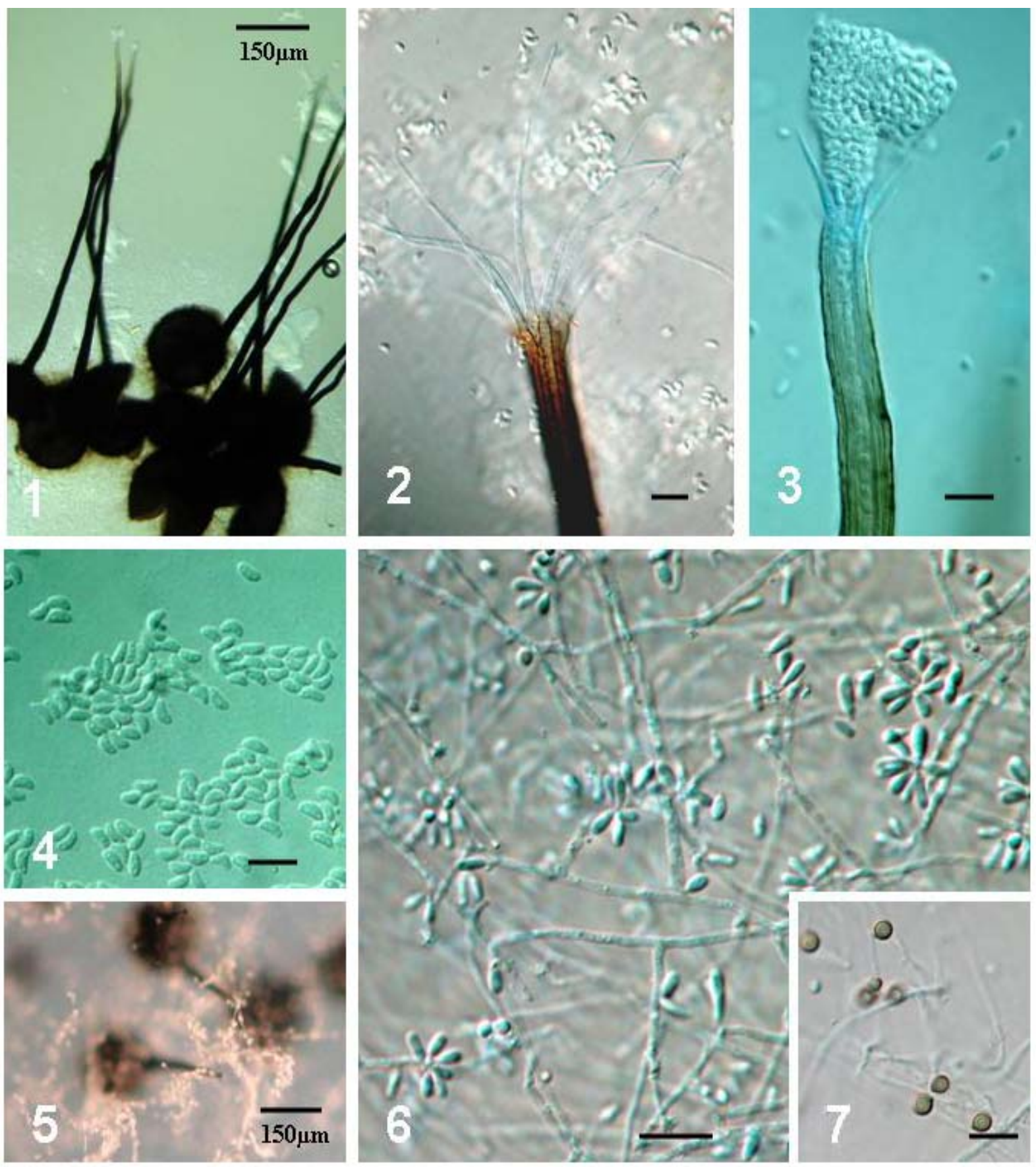

Figuras 2-7. Ophiostoma stenocerans . 1.- Ascomata de $O$. stenoceras en agar agua con trozos estériles de madera de pino. 2.- Ápice del cuello con hifas ostiolares ramificadas y ascosporas. 3.- Expulsión del canal ostiolar de las ascosporas en una masa mucoide. 4.- Ascosporas en vista lateral, alantoides, sin vaina mucilaginosa. 5. Cultivo en agar avena mostrando crecimiento de los peritecios de cuello largo e hifas con el anamorfo Sporothrix. 6.- Anamorfo en cultivo (agar avena) mostrando conidióforos micronematosos y células conidiógenas de proliferación simpodial denticulada (roseta) con conidios clavados a elípticos. 7.- Conidios secundarios subglobosos (Sporothrix schenckii ?) pigmentados, que nacen lateralmente sobre hifas indiferenciadas. Barra $=10 \mu \mathrm{m}$, salvo en Figura 1 y 5

desde una especie nativa como el espino (Acacia caven Mol.), inicialmente presente en ese ambiente, a la especie posteriormente cultivada en ese predio (Eucalyptus sp.), favoreciendo con ello el ingreso de nuevos patógenos. Es de suponer que este insecto descrito además en otras especies nativas como: Cryptocarya alba, Colliguaja 
odorifera, Lithraea caustica u otras, pueda adaptarse fácilmente a varios hospedadores vegetales cultivados.

La diversidad de anamorfos asociados a Ophiostoma y Ceratocystis, dos géneros morfológicamente semejantes, ha sido un carácter taxonómico útil en la definición de especies en ambos géneros, considerando las diferencias estructurales de los conidióforos y el tipos de desarrollo conidial. En el caso específico de Ophiostoma, surgen algunos problemas debido a que algunas especies pueden tener más de un anamorfo asociado (sinanamorfos), dentro de las 4 combinaciones posibles (ver Zipfel et al., 2006). Sporothrix, parece ser el más común anamorfo en Ophiostoma, presentando conidios simpodiales no septados en cortos dentículos sobre hifas indiferenciadas (De Hoog, 1974). Hyalorhinocladiella, no exhibe los dentículos típicos de Sporothrix; sin embargo, la distinción entre estos 2 géneros basada en la sola morfología, presenta a veces inconvenientes debido a las formas intermedias (Benade et al., 1996-1997). Pesotum (Graphium para algunos autores), es un anamorfo sinnematoso con células conidiógenas con proliferación anelídica generalmente simpodial (a veces percurrente) y conidios con dentículos prominentes en masas mucoides (Okada et al., 1998), mientras Leptographium posee conidióforos monotematosos oscuros que originan varias ramas que terminan en células conidiógenas con proliferación anelídica percurrente (o de apariencia simpodial) y conidios en masas mucoides (Wingfield, 1993; Jacob \& Wingfield, 2001).

Los integrantes del complex Ophisotoma stenoceras, como la mayoría de las especies del género, tienen ascomata peritecioides con largos cuellos (frecuentemente con más de uno por cada peritecio), que expulsan masas viscosas de ascosporas adaptadas a la dispersión por insectos (Upadhyay, 1981). Algunas especies que presentan ascomata cleistotecioides (sin cuello ni ostiolo), pero que mantiene todas las características del género, fueron separadas anteriormente por Parker (1957), en un género diferente (Europhium), pero actualmente al conocerse la variación que ejerce el tipo de ambiente sobre los cuerpos fructíferos, se considera un carácter taxonómico no estable. Posteriormente, Upadhyay (1981), incluye a Europhium en Ceratocystis y Harrington (1987) en Ophiostoma por la presencia de su anamorfo en Leptographium, mientras Zipfel et al. (2006), mediante estudios moleculares lo segregan de Ophiostoma por su linaje monofilético, incluyéndolo en Grosmannia, un género anteriormente descrito por Goidánich (1936), por presentar primariamente anamorfos en Leptographium.

El complex Ophiostoma stenoceras (Zhou et al., 2006), esta integrado por especies similare como: $\boldsymbol{O}$ dendifundum, $O$. stenocerans, $O$. narcissi, $O$. fusiforme, O. Iunatum, O. abietinum y O. aurorae, todas con anamorfos en Sporothrix. Este complex incluye $\boldsymbol{S}$. schenckii, la especie tipo del género y $\boldsymbol{S}$. inflata. Todos los integrantes del grupo no tienen el intrón 4 pero si el 5 del gen de la beta tubulina, sus ascosporas son reniformes, sin vaina y sus nichos ecológicos son generalmente la madera y el suelo (Aghayeva et al., 2004, 2005; Zhou et al., 2006).

O. stenoceras, es una especie bien conocida por los micólogos médicos, por su fase conidial casi indistinguible del patógeno humano $S$. schenkii y que fue considerada por Mariat (1971), como su anamorfo. Las relaciones de estos 2 taxa han sido objeto de muchas investigaciones y controversias en el pasado, sin embargo, los trabajos más recientes de Berbe \& Taylor (1992); Summerbel et al.(1993) y De Beer et al. (2003), confirman que $\boldsymbol{S}$. schenckii debe ser clasificado dentro del género teleomorfo Ophiostoma (complex $\boldsymbol{O}$. stenoceras), pero sus diferencias fisiológicas, asimilativas, morfológicas y moleculares, lo separan de éste y su anamorfo, principalmente por su poder patógeno en el hombre y los animales, su marcado dimorfismo termal, la ausencia de teleomorfo y su capacidad de crecimiento a $35-37^{\circ} \mathrm{C}$, con óptimos en $30^{\circ} \mathrm{C}$ (ver Summerbel et al., 1993). La biología molecular de las cepas de $\boldsymbol{S}$. schenckii aisladas desde fuentes humanas o de la naturaleza (suelo o madera), permiten separar sus integrantes en 2 clades que, según De Beer et al. (2003a), guardan relación con su distribución geográfica. Mesa-Arango et al., (2002) y Neyra et al.(2005), en estudios que incluyen la epidemiología, las formas clínicas y de distribución geográfica de esporotricosis humana, también dividen las cepas encontradas en México, Guatemala, Colombia, Perú y Bolivia en diferentes grupos que no siempre guardan relación con el sustrato o la patología, pero en mayor grado con distintos patrones geográficos. Los datos actuales parecen demostrar diferentes linajes genéticos dentro de las poblaciones de S. schenckii y que éstos prevalecen en diferentes regiones geográficas, detectando 3 mayores clades: todos los aislamientos Europeos, los de Brasil solamente y los de los restantes países de Sud América y Africa (Marimon et al., 2006).

Ophiostoma stenoceras, es un bien conocido colonizador de madera o suelo en el Hemisferio norte, que forma grupos monofiléticos que no se diferencian de los del Hemisferio sur; son hermanos de la clade formada por los aislamientos de $\boldsymbol{S}$. schenckii y tienen un óptimo crecimiento a $25^{\circ} \mathrm{C}$, mientras $\boldsymbol{S}$. schenckii lo hace a $30^{\circ} \mathrm{C}$ (De Beer et al., 1998). Poco se conoce de su presencia y distribución en el Hemisferio sur, salvo en Nueva Zelandia, Sudáfrica, Colombia y Uruguay, ni de su aparente registro en Chile (Farrel et al., 1997; De Beer et al., 1998, 2003a). Todos los teleomorfos encontrados en madera dura en el Hemisferio sur son morfológicamente similares a la cepa 
tipo de $\boldsymbol{O}$. stenocerans, sin embargo, sólo los aislamientos africanos presentan annuli en sus cuellos periteciales.

Seguramente el complex más conocido en el

Hemisferio sur es el de O.piceae (originario del Hemisferio norte), que incorpora varias especies patógenas forestales y es agente de azulado de la madera. Sus miembros, con seguridad introducidos en maderas de embalajes, se han reportado esporádicamente desde Nueva Zelandia, Australia, Chile, Brasil y Uruguay (Butin \& Peredo 1986; De Beer, et al., 2003b). En Chile especialmente, se han detectado varias especies de Ophiostoma introducidas, asociadas generalmente a insectos de la corteza (Coleoptera, Scolytidae) (O. araucariae; O. galeiforme, $O$. huntii, $O$. ips, $O$. piliferum, O. quercus, como también Ceratocystiopsis minuta) (Butin \& Peredo 1986; Zhou,et al.,2004).

En la actualidad los estudios filogenéticos basados en las secuencias de DNA, claramente indican el origen polifilético de los géneros Ophiostoma y Ceratocystis (Hausner et al., 1993; Spatafora \& Blackwell, 1994), confirmando el pensamiento de varios investigadores de las décadas del 1970-80 (De Hoog, 1974; von Arx, 1981; Harrington, 1981). Taxonómicamente, dentro de los Microascales (Sordariomycetes, Ascomycota), se incluye el grupo con los géneros Ceratocystis, Gondwanamyces Marais \& Wingfield, Sphaeronaemella Karst, Cormuvesica Vitjoen, Wingf \& Jacobson y sus anamorfos (Spatafora \& Blackwel, 1994; Hausner et al., 2000). Mientras en los Ophiostomatales (Sordariomycetes), en un estudio multigénico reciente que circunscribe los integrantes del género Ophiostoma sensu lato (Zipfel et al., 2006), indican 3 linajes monofiléticos con buen soporte estadístico que representan los 3 géneros teleomórficos anteriomente mencionados, apoyados por características morfológicas y posiblemente ecológicas. Las especies con anamorfos en Leptographium se agrupan juntas en el reinstalado género Grosmannia; las especies con anamorfos en Hyalorhinocladiella, sensibles a la cycloheximida, con cortos cuellos periteciales y ascosporas falcadas, en el reinstalado género Ceratocystiopsis y las especies con anamorfos en Sporothrix o Pesotum se retienen en Ophisostoma. A pesar, que este último taxa incluye muchas especies que evidencian ciertos subgrupos, estos autores prefieren no subdividirlo aún sin mayores estudios.

Nuestros aislados de Ophiostoma stenoceras asociados a la sintomatología detectada, presentaron solo anamorfos en Sporothrix y su diagnóstico fue confirmado en Sud Africa en Mayo del 2005, por el experto en el género, M.J Wingfield.

La presencia de conidios secundarios (sinanamorfos), encontrados solamente en una de las preparaciones efectuadas, merece un breve comentario debido a que éstos se observan esporádicamente sólo en los cultivos frescos de $\boldsymbol{S}$. schenckii. Su presencia, seguramente corresponde a una cepa de $\boldsymbol{O}$. stenoceras mezclada con mitosporas de $\boldsymbol{S}$. schenkii, situación que debe considerarse desde el punto de vista de la micología médica, como un hallazgo ecológico de asociación en un mismo vector, que interviene en la distribución de este patógeno primario escasamente detectado en el país en sólo 2 casos clínicos (Piontelli, 1995) y en zonas geográficas relativamente cercanas (Santiago).

\section{CONCLUSIONES}

E. buguetti puede causar daño forestal si su densidad poblacional es alta. Su asociación es benéfica con los hongos (alimento para sus larvas), pero la variada capacidad de dispersión fúngica en el ambiente circundante que puede ser integrada por variados hongos saprófitos, oportunistas o patógenos, constituye un potencial riesgo no solo forestal sino en salud pública (S.schenckii). O. stenoceras es considerado un saprófito o un débil oportunista, pero bajo ciertas condiciones ambientales y frente a hospedadores susceptibles podría causar mayores problemas que el azulado de la madera, lo que hace nacesario conocer su distribución en el país.

\section{REFERENCIAS}

Aghayeva, D.N.; Wingfield, M.J.; De Beer, Z.W.\& Kirisits, T. (2004). Two new Ophiostoma species with Sporothrix anamorphs from Austria and Azerbaijan. Mycologia 96:866-878

Aghayeva, D.N.; Wingfield, M.J.; Kirisits, T. \& Wingfield, B.D. (2005). Ophiostoma dentifundum sp. Nov. from oak in Europe, characterized using molecular phylogenetic data and morphology. Mycol. Res. 109:1127-1136

Benade, E.; Wingfield, M.J. 6 Van Wyk, P.S. (1996). Conidium development in the Hyalorhinocladiella anamorph of Ceratocystiopsis minuta-bicolor and Ophiostoma minus. Can J. Bot. 74:891-897

Benade, E.; Wingfield, M.J. 6 Van Wyk, P.S. (1997). Conidium development in Sporothrix anamorph of Ophiostoma. Mycol. Res. 101:1108-1112

Berbee, M.L. \& Taylor, J.W. (1992). 18S Ribosomal RNA gene sequence characters place the human pathogen Sporothrix schenckii in the genus Ophiostoma. Exp. Mycology 16:87-91

Butin, H. \& Peredo, H.L. (1986). Hongos parásitos en coníferas de América del Sur. Biblioteca Mycologica. J. Cramer, BerlinStuttgar

Cobos. A. (1953). Revisión de las Ectinogonia. spinola .sensu stricto. Coleóptero, Buprestidae. Revista Chilena de Entomología vol. 3: 41-68.Laboratorio de Entomología. Instituto de aclimatación-Almería, España. 
De Beer, Z.W.; Wittuhn, R.C.; Brito, H.; Wingfield, M.J.; Winfield, B.D.(1998). Phylogenetic placement of Ophiostoma stenoceras-like isolates from hardwoods in the Southern Hemisphere. ICPP98. Paper number 2.2.84

De Beer, Z.W.; Harrington, T.C.; Vismer,H.F.; Wingfield, B.D.; Winfield, M.J. (2003a). Phylogeny of the Ophiostoma stenocerans-Sporothrix schenckii complex. Mycologia 95:434441

De Beer, Z.W.; Wingfield, B.D.\& Winfield, M.J. (2003b). The Ophistoma piceae complex in the Southern Hemisphere: a phylogenetic study. Mycol. Res. 107:468-476

De Hoog, G.S. (1974). The genera Blastobotrys, Sporothrix, Calcarisporium and Calcarisporiella gen. nov. Studies in Mycology $7: 1-84$

De Hoog, G.S. \& Scheffer, R.J. (1984). Ceratocystis versus Ophiostoma: a reappraisal. Mycologia 76:292-299

Farrel, R.L.; Duncan,S.M.; Ram, A.P.; Kay, S.J.; Hadar, E.; Hadar, Y.; Blanchette, R.A.; et al., (1997). Causes of sapstain in New Zealand. In: Strategies for improving protection of logs and lumber (Kreber, B ed.). Proceeding of Symposium, Rotorua, New Zealand. FRI Bull. 204:25-29

Godánich, G. (1936). Il genere di Ascomiceti Grosmannia G. Goid. Bollettino della stazione di Patologia Vegetale di Roma 16:26-60

Grylls, B.T. \& Seifert, K.A. (1993). Asynoptic key to species of Ophiostoma, Ceratocystis and Ceratocystiopsis. In: Cerato-cystis and Ophiostoma. Taxonomy, ecology and pathogenicity. (Wingfield, M.J.; Seifert, K.A. \& Webber, J.F.eds.) American Phytophatological Society Press, St. Paul, Minnesota. USA. pp.261-268

Harrington, T.C. (1981). Cycloeximide sensivity as a taxo-nomic character in Ceratocystis. Mycologia 73:1123-1129

Harrington, T.C. (1987). New combinations in Ophiostoma of Ceratocystis species with Leptographium anamorphs. Mycotaxon 28:39-43

Harrington, T.C. (2005). Ecology and evolution of mycophagous bark beetles and their fungal partners. In: Insect-Fungal associations: Ecology and Evolutions (Vega, F.E. \& Blackwell, M. eds.). Oxford University Press, N.York. pp.1-22

Hausner, G.; Reid, G.\& Klassen, G.R. (1993). On the phylogeny of Ophiostoma, Ceratocystis s.s. and Microascus, and relationships within Ophiostoma based on partial ribosomal DNA sequences. Can. J. Bot. 71.1249-1285

Hausner, G.; Reid, G.\& Klassen, G.R. (2000). On the phylogeny of members of Ceratocystis s.s. and Ophiostoma that posses different anamorphic states, with emphasis on the anamorph genus Leptographium, based on partial ribosomal DNA sequences. Can. J. Bot. 78:903-916

Hunt, J. (1956). Taxonomy of the genus Ceratocystis. Lloyd 19:1-58

Jacobs, K. \& Wingfield, M.J. (2001). Leptographium speciestree pathogens, insect associated and agents of blue-stain. American
Phytophatological Press, St. Paul, Minnesota. USA

Kowalski, T. \& Butin, H. (1989), Taxonomie bekannter und neuer Ceratocystis-Arten an Eiche (Quercus robur L.). Phytopathol. Z. 124:236-248

Mariat, F.(1971). Adaptation de Ceratocystis stenocerans (Robak) C. Moreau à la vie parasitaire chez l'animal. Etude de la souche sauvage et des mutants pathogens. Comparison avec Sprothrix schenckii Hektoen et Perkins. Rev. Mycol. 36:3-25

Marimon, R.; Gené, J.; Cano, J.;Trilles, L.; Dos Santos Lazéra., Guarro, J.(2006). Molecular phylogeny of Sporothrix schenckii. J. Clin. Microbiol. 44:3251-3256

Mesa-Arango, A.C.; Reyes-Montes, M.del R.; Pérez-Mejía, A.; Navarro-Barranco, H.; Souza, V.; Zuñiga, G.; Toriello, C. (2002).Phenotyping and Genotyping of Sporothrix schenckii isolates according to Geographic origin and clinical form of sporotrichosis. J. Clin. Microbiol. 40:3004-3011

Neyra,E.; Fonteyne, P-A.; Swinne, D.; Fauche,F.; Bustamente, B.; Nolard,N. (2005). Epidemiology of human sporotrichosis investigated by amplified fragment leng polymorphism. J.Clin. Microbiol. 43:1348-1352

Okada, G.; Seifert, K.A.; Takematsu, A.; Yamaoka, Y.; Miyazaki, S.; Tubaki, K. (1998). A molecular phylogenetic reappraisal of the Graphium complex based on 18S rDNA sequences. Can.J. Bot. 74:1495-1506

Parker, A.K. (1957). Europhium, a new genus of the Ascomycetes with a Leptographium imperfect states. Can. J. Bot. 35:173-179

Piontelli, E. (1995). Historia de la micología Chilena. Rev. Iberoam. Micol. 12: 86-89

Samuels, G. (1993). The case for distinguishing Ceratocystis and Ophiostoma. In: Ceratocystis and Ophiostoma. Taxonomy, Ecology and Pathogenicity (Wingfield, M.J.; Seifert, K.A. \& Webber, J.F. eds.). APS Press. pp.15-20

Spatafora, J.W \& Blackwell, M. (1994).The polyphyletic origin of ophiostomatoid fungi. Mycol.Res. 98:1-9

Summerbel, R.; Kane, J.; Krajden, S. \& Duke, E. (1993). Medically important Sporothrix species and related Ophiostomatoid Fungi. In: Ceratocystis and Ophiostoma. Taxonomy, ecology and pathogenicity. (Wingfield, M.J.; Seifert, K.A. \& Webber, J.F.eds.) American Phytophatological Society Press, St. Paul, Minnesota. USA. pp.185-192

Upadhyay, H.P. (1981). A monograph of Ceratocystis and Ceratocystiopsis. The university of Georgia Press, Athens. C.A.

Von Arx, J.A. (1981). The genera of fungi sporulating in pure culture.3nd edition. J. Cramer, Lehere, Germany

Wingfield, M.J.;Seifert, K.A. \& Webber, J.F. (1993). Ceratocystis and Ophiostoma. Taxonomy, ecology and pathogenicity. American Phytophatological Society Press, St. Paul, Minnesota. USA.

Wingfield, M.J. (1993). Leptographium species as an anamorphs of Ophiostoma: Progress in establishing acceptable generic and species concepts. In: Ceratocystis and Ophiostoma. Taxonomy, ecology and pathogenicity. (Wingfield, M.J.; Seifert, K.A. \& 
Webber, J.F.eds.) American Phytophatological Society Press, St. Paul, Minnesota. USA. pp.43-51

Zipfel, R.D.; de Beer, Z.W.; Jacobs, K.; Wingfield, B.D.; Wingfield, M.J. (2006). Multigene phylogenies define Ceratocystiopsis and Grosmannia distinct from Ophiostoma. Stud. Mycol. 55:75-97

Zhou, X.; de Beer, Z.W.; Ahumada, R.; Wingfield, B.D.; Wingfield, M.J. (2004).Ophiostoma and Ceratocystiopsis spp.
Associated with two pine-infesting bark beetles in Chile. Fungal Diversity- 261-275

Zhou, X.; de Beer, Z.W. \& Wingfield, M.J. (2006). DNA sequence comparisons of Ophiostoma spp., including Ophiostoma aurorae sp. Nov., associated with pine bark beetles in South Africa. Studies in Mycology 55: 269-277 